\section{Acquired restrictive strabismus in infancy associated with neurofibromatosis type 2}

\section{Estrabismo restritivo adquirido na infância associado à neurofibromatose tipo 2}

Dear Editors:

We would like to add some new information regarding the patient described in the paper entitled, "Surgical treatment of acquired restrictive strabismus in infancy: case report", published in Arquivos Brasileiros de Oftamologia in 2009(1). We stated that the diagnosis in the reported case was unclear despite extensive investigations.

After surgical treatment of acquired restrictive strabismus, the child described remained stable with no other symptoms for approximately 7 years. By the age of 14 years, he developed left hand palsy
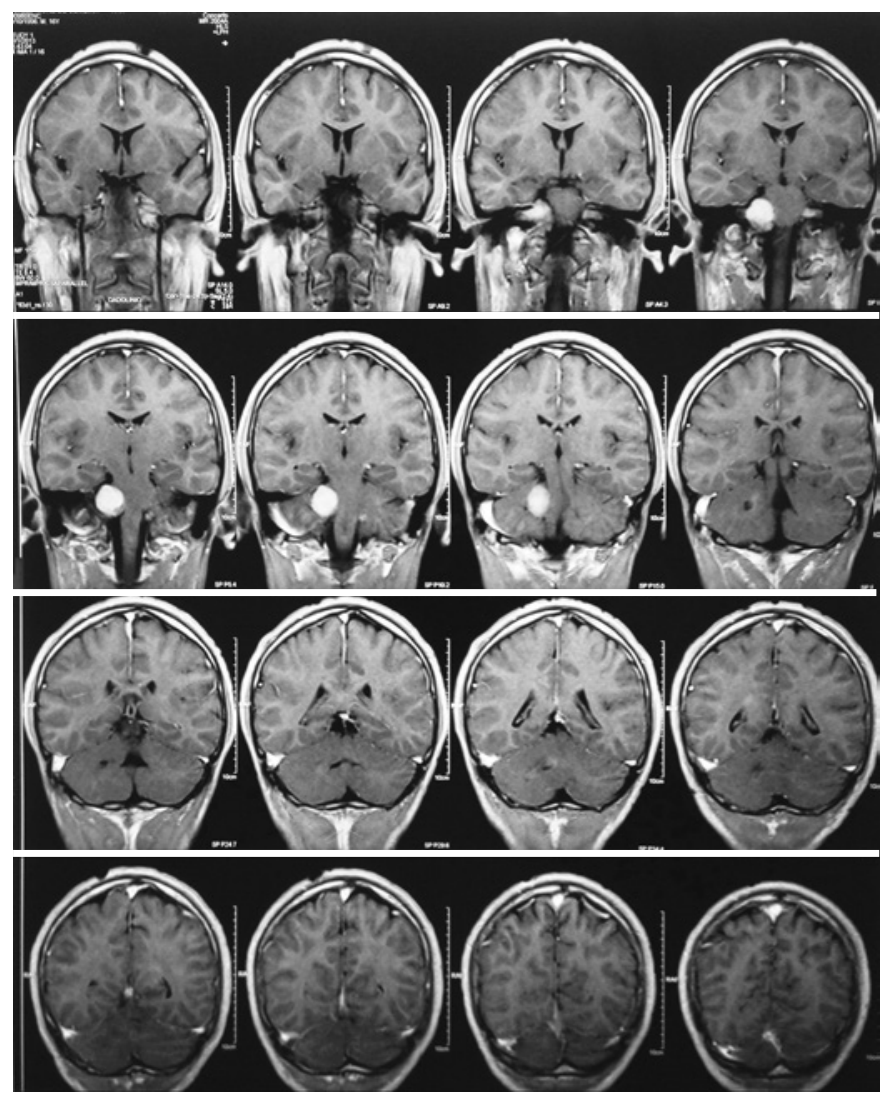

Figure 1. Magnetic resonance imaging with gadolinium demonstrating bilateral vestibular schwannomas with size predominance on the right side. and skin tumors. One year later, he started experiencing the beginnings of a hearing loss. Magnetic resonance imaging (MRI) of the brain revealed bilateral tumors indicative of vestibular schwannoma (Figure 1).

Subsequently, the patient was referred to the Neurofibromatosis Reference Center of the Universidade Federal de Minas Gerais for further evaluation. Diagnosis of neurofibromatosis type 2 (NF2) was then established according to MRI demonstrating bilateral vestibular schwannomas associated with cutaneous schwannomas.

NF2 is a dominant, autosomal disease characterized by bilateral vestibular schwannomas with multiple nervous system and skin tumors and is often associated with ocular abnormalities. Although classically considered a disease of adults, the initial signs and symptoms of NF2 may be evident in childhood and often goes unrecognized(2). Diagnosis is difficult in the majority of cases because of its rarity. Initial manifestations of NF2 differ between children and adults. The first sign of disease severity in patients with early-onset NF2 predominantly comprise ocular presentations and weakness in lower motor neuron extremities as opposed to impairment of the eighth nerve in cases of late disease onset ${ }^{(3)}$.

Approximately $50 \%$ of NF2 patients present with strabismus, typically associated with tumors and palsies of cranial nerves III, IV, and $\mathrm{Vl}\left({ }^{(4)}\right.$. Although restrictive strabismus is not commonly reported in patients with NF2, it is possible that it was associated with early onset of NF2 in our patient.

Vanessa Waisberg ${ }^{1}$, Galton Carvalho Vasconcelos ${ }^{1}$ Ana Rosa Pimentel de Figueiredo', Débora Marques de Miranda², Juliana Ferreira de Souza ${ }^{3}$, Luiz Oswaldo Carneiro Rodrigues

Submitted for publication: September 29, 2015

Accepted for publication: January 23, 2016

Departamento de Oftalmologia, Universidade Federal de Minas Gerais, Belo Horizonte, MG, Brazil. Departamento de Pediatria, Universidade Federal de Minas Gerais, Belo Horizonte, MG, Brazil.

Departamento de Clinica Médica, Universidade Federal de Minas Gerais, Belo Horizonte, MG, Brazil.

Funding: No specific financial support was available for this study.

Disclosure of potential conflicts of interest: None of the authors have any potential conflict of interest to disclose.

Corresponding author: Vanessa Waisberg. Av. Brasil, 691 - 4a andar - Belo Horizonte, MG 30140-000 - Brasil - E-mail: vanessawaisberg@hotmail.com

\section{REFERENCES}

1. Damasceno JV, Vasconcelos GC, Figueiredo AR, Almeida HC. [Surgical treatment of acquired restrictive strabismus in infancy: case report]. Arq Bras Oftalmol. 2009;72(1): 119-22. Portuguese

2. Evans DG, Birch JM, Ramsden RT. Paediatric presentation of type 2 neurofibromatosis Arch Dis Child. 1999:81(6):496-9.

3. Bosch MM, Boltshauser E, Harpes P, Landau K. Ophthalmologic findings and a long-term course in patients with neurofibromatosis type 2. Am J Ophthalmol. 2006; $141(6): 1068-77$.

4. Feucht M, Griffiths B, Niemüller I, Haase W, Richard G, Mautner VF. Neurofibromatosis 2 leads to higher incidence of strabismological and neuro-ophthalmological disorders. Acta Ophthalmol. 2008;86(8):882-6. 